\title{
Sling Suspension Therapy Utilization in Musculoskeletal Rehabilitation
}

\author{
Mohammad Nasb, Zhenlan Li* \\ Department of Rehabilitation Medicine, First Hospital of Jilin University, Jilin University, Changchun, China \\ Email:mmn87@yahoo.com, "zhenlanli66@163.com
}

Received 9 May 2016; accepted 15 July 2016; published 18 July 2016

Copyright $\odot 2016$ by authors and Scientific Research Publishing Inc.

This work is licensed under the Creative Commons Attribution International License (CC BY). http://creativecommons.org/licenses/by/4.0/

(c) () 0 pen Access

\begin{abstract}
The development of an effective and inexpensive device to restore and enhance the human musculoskeletal functions is of particular interest. Sling exercise therapy (SET) is one of the most effective developed tools in rehabilitation of musculoskeletal disorders, which has been successfully used in various applications ranging from diagnosis to treatment. To the best of our knowledge, SET has never been comprehended and reviewed previously. Therefore, it was highly required to further understand the role of SET in various therapeutic applications. Inspired by this herein, this study is dedicated to emphasize the advancement in utilization of the SET in both diagnosis and treatment as well as their related challenges. This would be concluded by future perspectives of the SET.
\end{abstract}

\section{Keywords}

Rehabilitation, Sling, Muscle Training, SET, Sling Exercise Training, Neurac

\section{Introduction}

There are various serious diseases affected thousands of people around worldwide such as low-back pain (LBP) and stroke. Those are subsequently requiring a highly efficient rehabilitation method. Predominately, the hydrotherapy, electrotherapy, and exercise therapy are the most common approaches utilized for musculoskeletal rehabilitation. SET is among most promising approach due to its low-cost, efficiency, and easiness. Furthermore, SET not only promises rapid recovery but also acts as diagnostic tool for detection of biomechanical chain defects.

In particular, SET is based on slings attached to a particular part of human body using ropes and pulleys inside a sling system aiding to treat the impairments [1]. There are two main categories of the SET including a

${ }^{*}$ Corresponding author. 
traditional SET that is usually used for simple training [2]. While Neurac involves a high level of neuromuscular activation which lead to strengthening muscles, improvement of the sensorimotor/balance, increasing range of motion (ROM), and resolution of pain as well as clinical diagnoses for different impairments. For example, various studies reported the significant effect of SET on restoration of the muscle skeletal functions after stroke and LBP in addition to improving the respiration and chest expansion [3]-[6].

Furthermore, SET has the ability to achieve multi-goals at the same time. For instance, Lee and coworkers reported the substantial effect of Neurac technique-based training on pain reduction, enhancement balance, regression fatigability, and treatment of chronic neck pain [7].

Although SET made massive progress in the rehabilitation centers, but there are no previously reported reviews on the experimental results of SET. In pursuit of this aim, this review is dedicated to synopsize the most significant findings of SET in the therapeutic and diagnostic applications. This includes using SET in rehabilitations after sport injuries, stroke and LBP. This will be concluded with the current challenges and future prospective of SET.

\section{A Brief History of SET}

In the past several decades SET is used as an effective strategy for treatment of muscle skeletal impairments. In the beginning of twentieth century, the first model of SET called sling table was developed, that was used for helping the injured soldiers. Later, SET was successfully extended to cure the patients affected by paralysis and poliomyelitis that struck European countries such as Germany and England [23] [25]. In late 1940s SET combined with hydrotherapy posed a substantial effect onto the rehabilitation of patients affected by polio virus. Thereafter, In Norway, since the 1960s SET paved a novel way for treatment of the impairments in the shoulders and hips [26]-[28]. This subsequently triggered scientists to develop various models of sling suspension systems for enabling their beneficent usage in different rehabilitation centers and hospitals (Figure 1). The various applications of SET, ranging from diagnostics to therapy are tabulated in Table 1. For example, SET is successfully used for treatment of LBP that is considered to be one of the most common serious diseases among

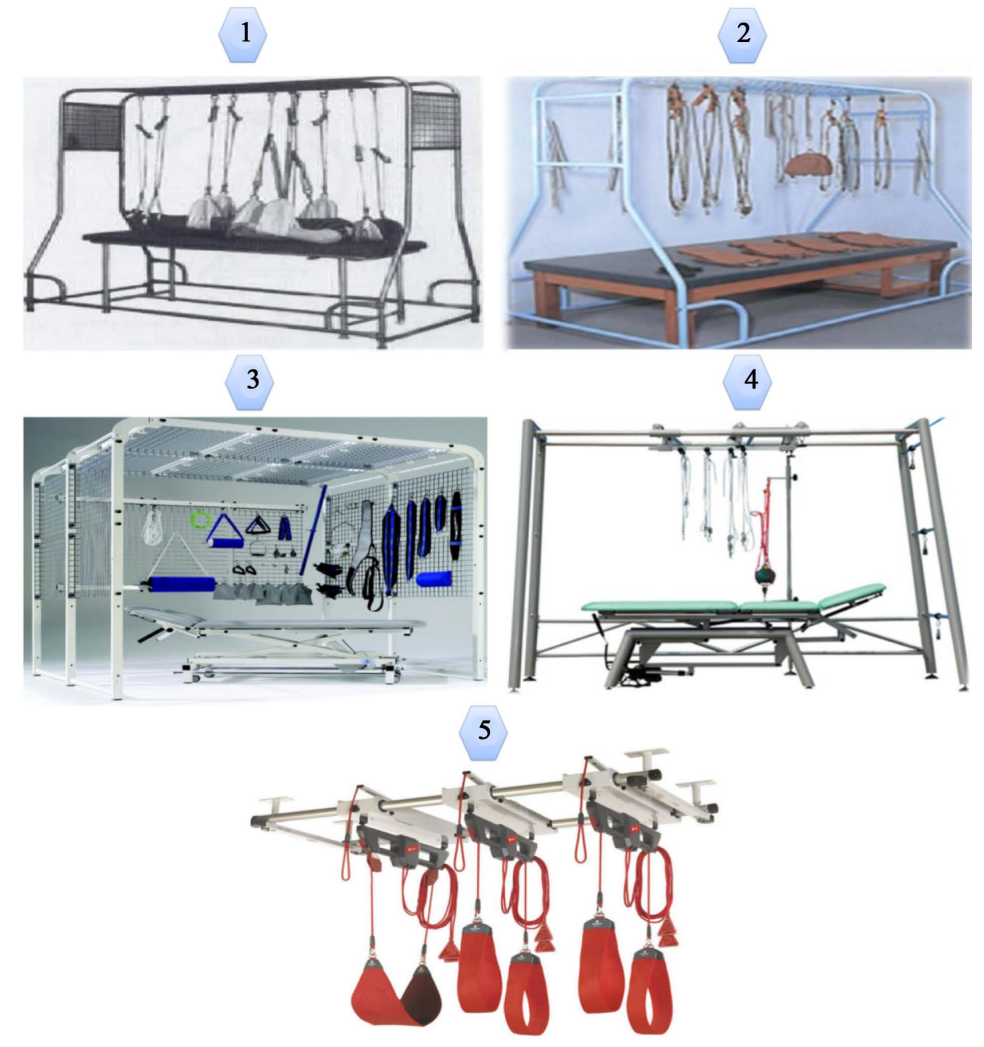

Figure 1. Various sling suspension systems models that were developed over the past century. 
Table 1. Various applications of SET.

\begin{tabular}{|c|c|c|c|}
\hline & SET usage & Efficiency and/or Results & References \\
\hline \multirow{6}{*}{ Therapeutics } & Range of motion & Improve ROM & [8] [9] \\
\hline & Open/close kinetic chain & Feasible for using both of Open/close kinetic chain exercises & [10] \\
\hline & Sensorimotor/balance & Enhance balance and proprioceptive & [4] [11] \\
\hline & Stabilizing system & Increase the durability of the joints and muscles during training & [12]-[15] \\
\hline & Muscle training & Vulnerable for applying various simultaneous exercises for multi-muscles & [16]-[22] \\
\hline & Relax/relief pain & Decrease pain along with enhance muscles relaxation & [4] [8] [15] \\
\hline \multirow{2}{*}{ Diagnostics } & Weak link testing & $\begin{array}{l}\text { Facilitates detection of the impairments between } \\
\text { the deep stabilizer and superficial prime mover muscles }\end{array}$ & [23] \\
\hline & Holding time & Examination the stability of the deep muscles under neutral position & [24] \\
\hline
\end{tabular}

adults which are always requiring highly complicated, costly, and inefficient therapeutic methods. Alternatively, SET possesses many advantages for LBP over the other approaches due to its considerable effect on muscles and nerves [29]. For instance, Zi-yun and coworker studied the substantial effect of SET on the nonspecific LBP patients. They concluded that SET led to a significant pain relief via exercise training [30]. Likewise, SET with stable and unstable bridging exercises accelerated curing process of LBP patients with less pain relative to its counterpart traditional exercises [12].

\section{SET Parameters}

There are various factors that can be utilized during SET for allowing its maximum effects in both therapeutics and diagnostics. These include ropes level, vibration, and positions. In particular, there are three main types of supporting ropes including single, double, and pulley, which can be adjusted relative to the case. For example, multi-point suspensions at different angels beget a better therapeutic efficiency for various individuals. Furthermore, multi-points suspension stimulates the target muscles without pain because the body weight is loaded by the bungees assuring safety [31]. This offers many advantageous. In contrast, single-point suspension offers a low degree of safety during exercise as well as weight bearing (Figure 2). For instance, Kanehisa and coworkers reported that the muscles are activated well in the LBP patient upon usage of SET relative to the groundbased push-ups exercise via engaging into the multi-suspension SET. Specifically, the activation in the upper limb and anterior trunk muscles are significantly improved compared to the ground-based push-up exercise [19]. It is noteworthy that, elasticity of the used cords during SET can be used to assist or resist the muscles movements, enabling their facile restoring. Those are subsequently being adapted according to the current muscles strength to shorten the treatment time. This is ascribed to the fact that, the patient's body is fully bearded by the ropes resulting in reducing their stress during training.

Vibration is also another decisive factor in SET due to its unique ability onto the muscle's contraction [16]. This does not only have a substantial effect onto boosting the muscle activities but also relieves pain [32]-[35]. Moreover, different from the mat-exercise, adding vibration during the SET boosts muscle activity muscles increase without pain. There are fully investigated studies over wide varieties of muscles by tuning the vibration frequency value and exercise type as tabulated in Table 2. For example, Kang and coworker reported that, the stimulation of trunk muscles (e.g. internal oblique, rectus abdominis, multifidus, and erector spinae) by using vibration with SET was significantly superior to SET [33] Interestingly, Yoo and coworkers studied the effect of various frequencies of vibration on stimulation the serratus anterior muscle. The stimulation at a vibration of 50 $\mathrm{Hz}$ was significantly higher than that of $30 \mathrm{~Hz}$ and $90 \mathrm{~Hz}$ respectively [34] (Table 2).

Various positions are available during the SET which allow exercise of different muscles concurrently. In addition, patients' position could be adapted according to their individual case especially those suffering from the chronic diseases and/or serious injuries. Furthermore, SET is suitable for training a group of patients' simultaneously to prevent a bizarre environment that maybe created if patients are treated individually. That is not only favored socially but also preserves time and effort of the physiotherapists. 


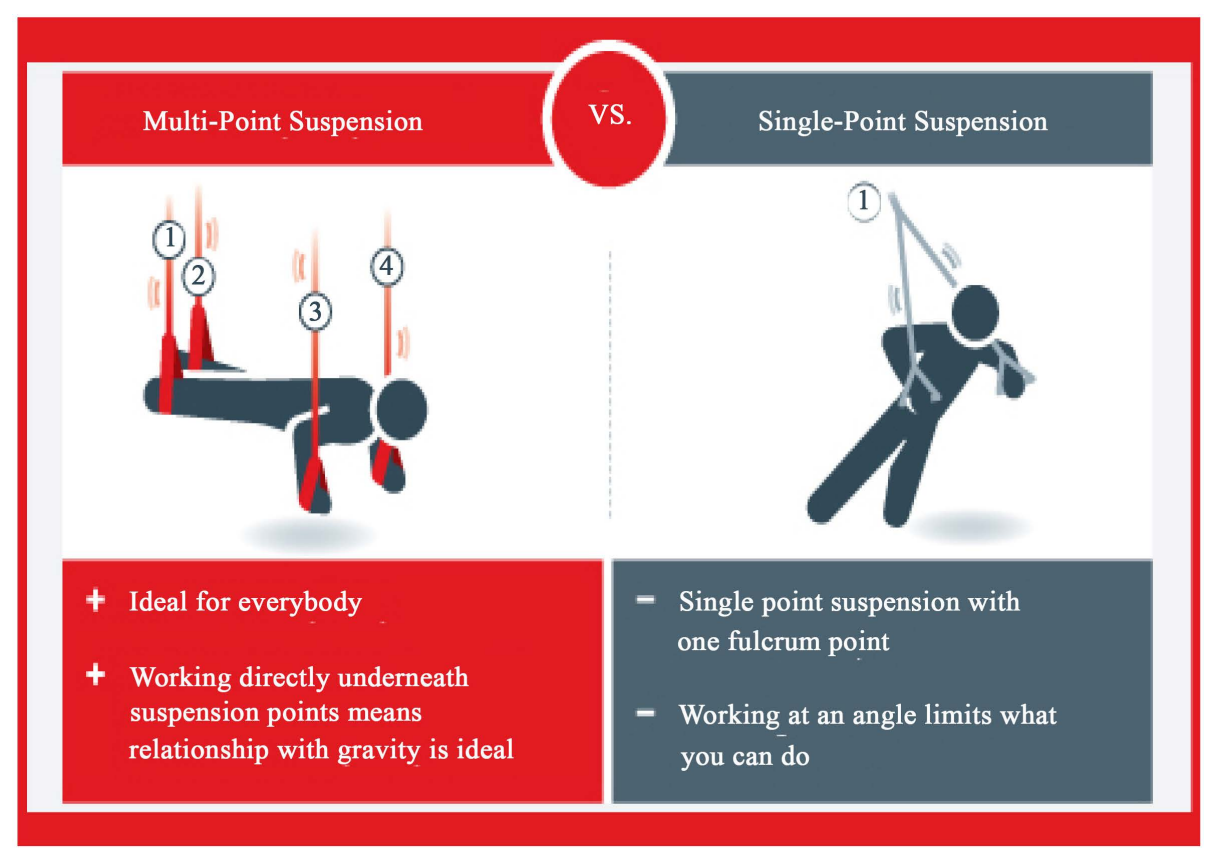

Figure 2. Scheme shows the difference between SET by using multi-point suspension and single-point suspension, Adapted with permission from. Justin Grinius and Rebalanced SF Copyright @ 2016.

Table 2. Comparison between the SET and SET with vibration on the muscles activities. All the studded subjects were adult males.

\begin{tabular}{ccccccccc}
\hline \multirow{2}{*}{ Muscles name } & Frequency(Hz) & Subjects & NO. & Exercise & \multicolumn{2}{c}{ Muscle activity } & P & References \\
& & & With vibration & Without vibration & & \\
\hline Internal oblique & 1024 & 11 & supine bridge & $17.90 \pm 12.61$ & $11.52 \pm 9.25$ & $<0.01$ & {$[32]$} \\
Rectus abdominis & 1024 & 11 & supine bridge & $3.78 \pm 3.12$ & $2.46 \pm 1.99$ & $<0.05$ & {$[32]$} \\
Multifidus & 1024 & 11 & supine bridge & $36.53 \pm 6.05$ & $30.05 \pm 5.13$ & $<0.01$ & {$[32]$} \\
Erector spinae & 1024 & 11 & supine bridge & $31.01 \pm 8.56$ & $24.87 \pm 8.02$ & $<0.01$ & {$[32]$} \\
Serratus anterior & 50 & 10 & push-up plus & $85.6 \pm 18.8 \%$ & $64.8 \% \pm 16.7 \%$ & $<0.05$ & {$[34]$} \\
Serratus anterior & 30 & 10 & push-up plus & $76.5 \pm 15.6 \%$ & $64.8 \% \pm 16.7 \%$ & $>0.05$ & {$[34]$} \\
Serratus anterior & 90 & 10 & push-up plus & $66.1 \pm 17.6 \%$ & $64.8 \% \pm 16.7 \%$ & $>0.05$ & {$[34]$} \\
Upper trapezius & 3.5 & 15 & push-up & $0.057 \pm 0.010$ & $0.034 \pm 0.013$ & $<0.05$ & {$[33]$} \\
Lower trapezius & 3.5 & 15 & push-up & $0.053 \pm 0.009$ & $0.025 \pm 0.008$ & $<0.05$ & {$[33]$} \\
Serratus anterior & 3.5 & 15 & push-up & $0.083 \pm 0.014$ & $0.051 \pm 0.012$ & $<0.05$ & {$[33]$} \\
\hline
\end{tabular}

\section{SET Advantages}

\subsection{Balance and Sensorimotor Training}

Balance is a complicated motor skill that is shaped by interplay between various sensorimotor processes, environment's effects, and functional events [36]. Balance impairment may affect human movement and/or muscle's tone negatively [37]. There are various factors determining the balance impairment including but not limited to weakness of the muscle in the lower limbs, shoulder, and back [38]-[40].

SET is one of the most efficient systematic tools for treatment of balance impairment via sensorimotor training [13]. This is achieved by using a closed kinetic chain on an unstable supporter surface to obtain ultimate stimulation of the sensory-motor system [41]. In particular, sensorimotor training on an unstable supporter lead- 
ing to redistribution of muscles tone, activation of balance coordination, and increasing the sensory feedback via counterbalancing among both nervous and muscles system. Consequently, balance is restored through enhancement of the feed-back response of the motor system, co-contraction levels, and joint stability [4] [20]. In this regard, various reports revealed that, sensorimotor training on an unstable surface drove the activation of various co-contracted muscles such as deltoid, triceps, and spine muscles. This is more efficient, and comfortable relative to the traditional exercise [42]. Intriguingly, Hwangbo and Lehman reported that, sensorimotor training on an unstable surface along with muscle stimulation improve the joint proprioception [11] [43] This is owing to the substantial effect of sensorimotor on improvement of muscles control and joints stability along with facilitating their normal response restoration [4] [44]. Another efficient tool for providing unstable surface during SET, is through deployment of foam mats, tilt board, Swiss balls, and air-filled rubber cushions ascribed to their effect on enhancement muscles' stress and activation and improvement of joint Proprioception [45]. For instance, Murphy and coworker reported that, the activity of triceps muscle in presence of unstable surface was significantly superior to both, inclined surface and stable surface respectively (Figure 3). This is ascribed to the greater muscles stress load under unstable surface condition which ultimate decrease their force output and activity [46].

Notably, SET exercise is an efficient strategy for multi-planar balance training for improvement in the joints stability to enable maximum body balance that cannot be easily achieved through classical training methods.

In addition to aforementioned benefits, SET also plays a paramount role in protection of athletics injuries along with improvement in their performance. Most of the athletics injuries are usually resulting from decreasing their body balance that maybe diminished via balance exercise with assistance of the SET [47] [48]. For instance, the ankle sprain and acute knee injuries were declined by around (50\%) and (54\%) respectively upon usage of SET training [49]. In addition the athletics performances were tremendously improved including, throwing velocity, balance of Taekwondo players, and body-flexibility [50]-[52] were improved significantly by SET. Most importantly, the balance rehabilitation process for the athletics through SET training is a fast and efficient therapy. This is owing to ability of SET to achieve simultaneous multi-target functions including balance restoration, enhancing proprioception, and muscles control.

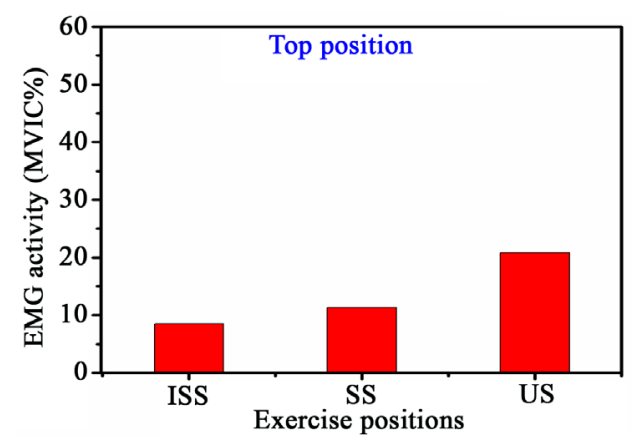

(a)

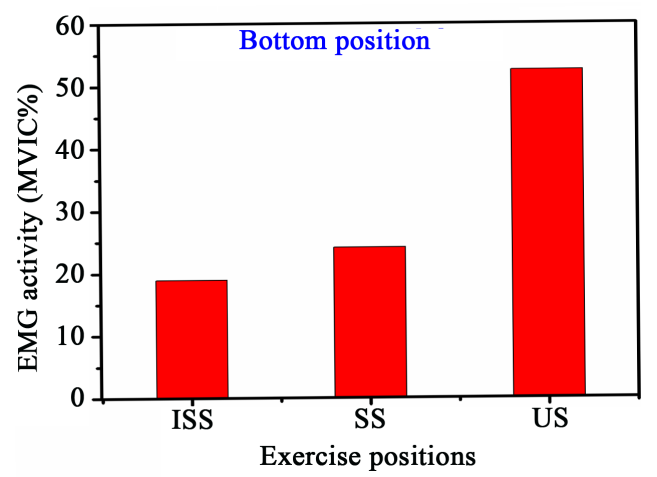

(b)

Figure 3. EMG activity recorded for the different muscles for Triceps muscle at the top and bottom of the push-up task performed on an incline stable surface (ISS), stable surface (SS), and unstable surface (US). This image was drawn based on the data from [46]. 


\subsection{Diagnostic System}

SET can act as a platform for diagnosing the biomechanical chain disorders. This is based on measurement of the muscles tolerance through progressive weight-loading via using open and closed kinetic chain exercises. This is achieved by two main tests-the holding time and weak link. In particular, the holding time test is used to examine the stability of the deep muscles by weight loading as a function of holding time under neutral position. Specifically, reduction in the holding time relative to standard is an indication for muscles weakness at a particular position that should be the starting point for the muscles training with isometric exercises. For example, chronic low back pain (CLBP) can be diagnosed by detecting the weakness of its correlated muscles through the holding time test [24]. Compared with the traditional diagnostic routes such as manual muscles test and EMG, SET is more comfortable, facile, and low-cost.

On the other hand, the weak link test entails using a closed kinetic chain in a progressive ladder system until the patient couldn't perform the exercise correctly or the pain is experienced. This is based on detection of the impairments during interaction between the deep stabilizer muscles and superficial prime mover muscles. Accordingly, the treatment begins with adjusting the dynamic movements at a level where the movement could be done successfully without pain [24]. Then, the muscles should be tested individually using an open kinetic chain exercises to determine the impairment's site. The weak link test is using effectively for sensing of various muscles strength disorders as figured in (Figure 4). For example, experience of severe pain during the trunk extension exercise and/or inability of patient to perform it, reflects the presence of one or more weak links in the lumbar spine region. It should be noticed that, for an accurate investigation, therapist should consider the fact that different muscles are responsible for the same movement during the closed kinetic chain exercise test [23]. Eventually, the weak link test can be a prior step in the athletics rehabilitation to determine their muscle disorders swiftly along with identification of treatment method.

\subsection{Muscle Training}

SET is a liable method for training muscles to enable their selective strengthening ability and activation. This is mainly depending on type of SET exercise and its correlated supporting surfaces. Various previous studies reported the substantial effect of SET on the muscles training [53]-[56]. Thus, SET can serve to achieve ultimate muscles activation during performance of many exercises such as push-up, back extension, and knee extension. This is not only effective but also selective approach because therapist can discard the normal muscles during

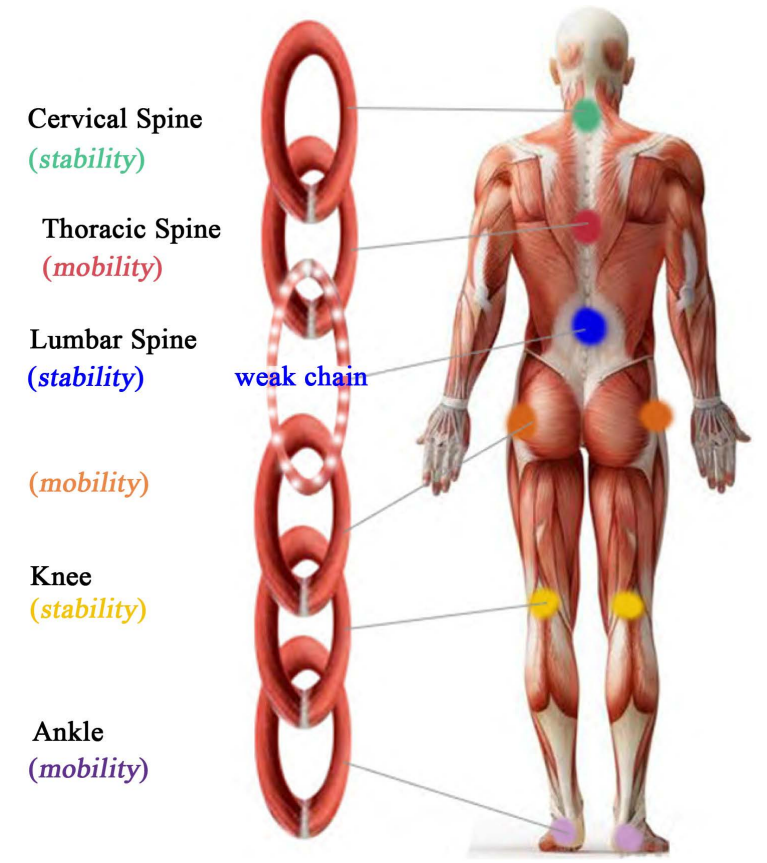

Figure 4. Co-relationship between kinetic chain-link test and human body musculoskeletal system. 
SET training via application of proper SET conditions (e.g. positions, cords numbers and type). Yoon and coworkers investigated the effect of Neurac sling exercise on adjusting the postural balance and muscles response in CLBP [4]. The results revealed that, Neurac sling enhanced the muscles response patterns of CLBP patients which is an essential factor of rehabilitation procedure [57] [58]. Recently, Kanehisa and coworkers compared systematically between the muscles' activities during sling-and ground-based push-up exercise (Figure 5). The results clearly warrant that, the sling-based push-up exercise led to greater activation in the upper limb and anterior trunk muscles relative to the ground-based push-up exercise, attributed to the stabilization effect [19]. It is noteworthy that, the second level of muscles strength (2/5) is deeply required to perform the sling-based training. Also SET is not suitable in presence of an acute stage of some diseases or injuries (e.g. Achilles tendon rupture).

The sling-based training in presence or absence of unstable surfaces is a unique tool for improvement of the muscle activation and its related function [55] [59]. For instance, most recently lee and coworkers systemically investigated the difference in the muscles activities during the plank position on stable ground (ST), unstable ground (US), and on suspension device (SL) (Figure 6). The results reflected the superior efficiency of SET training (SL) on the electromyography activity of muscles including right external oblique (REO), left external oblique (LEO), left rectus abdominal (LRA), right erector spinal (RES), left erector spinal (LES), and right erector spinal (RRA) relative to US-plank and ST-plank [60] [61] (Figure 6(d)).
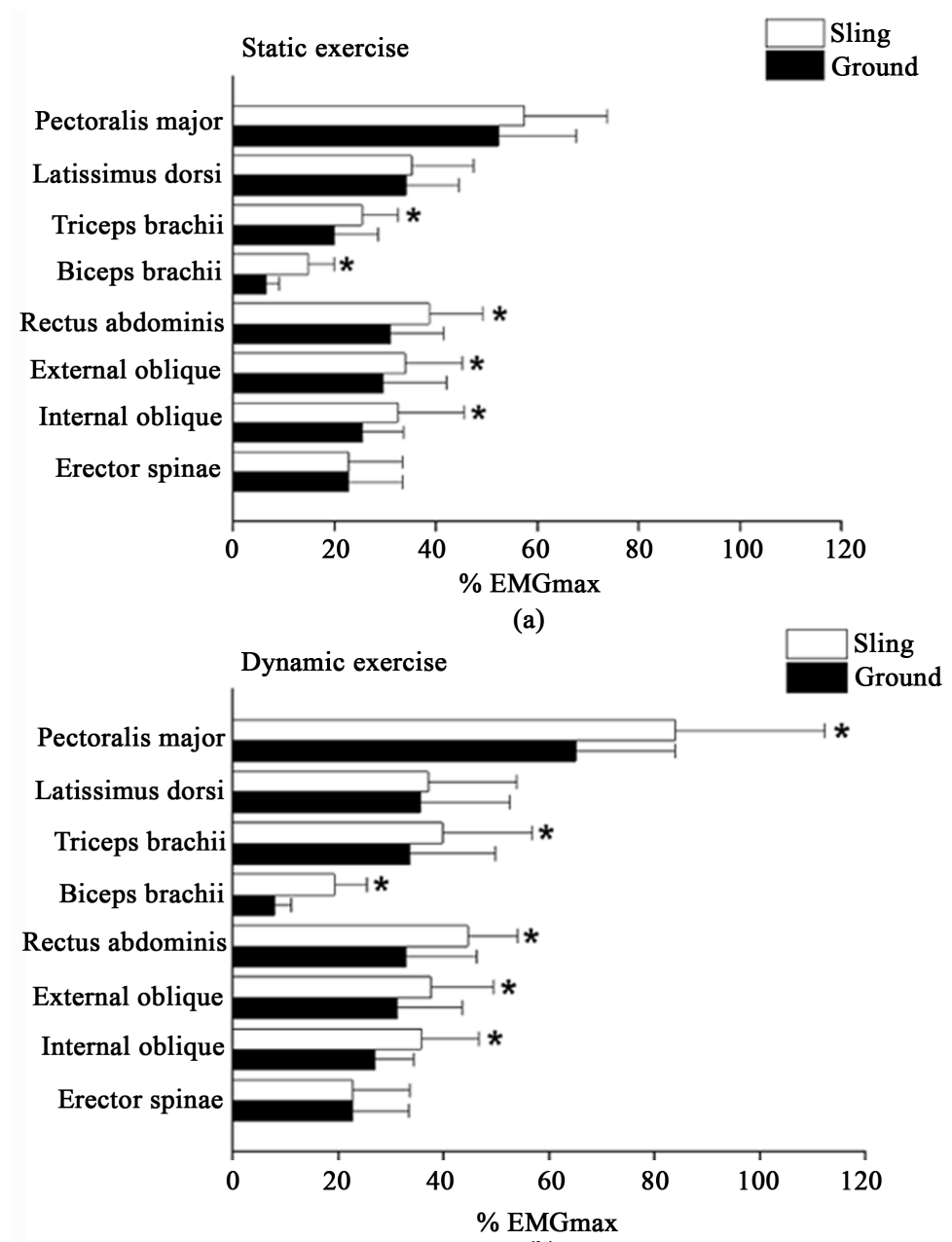

(b)

Figure 5. (a) Comparison of the muscular activity levels during the dynamic push-up exercise in the sling and the ground; (b) Muscular activity levels during the static push-up exercise in the sling and the ground. Note: the mark $(*)$ indicates that \% EMGmax in the sling condition is considerably greater $(\mathrm{P}$ $<0.05)$ than that of the ground condition. Adapted with permission from [19], Copyright BioMed Central Ltd. 2014. 


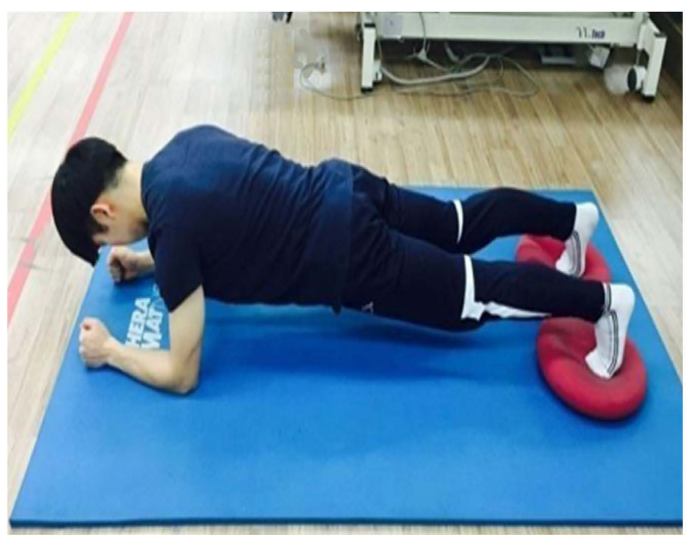

(a)

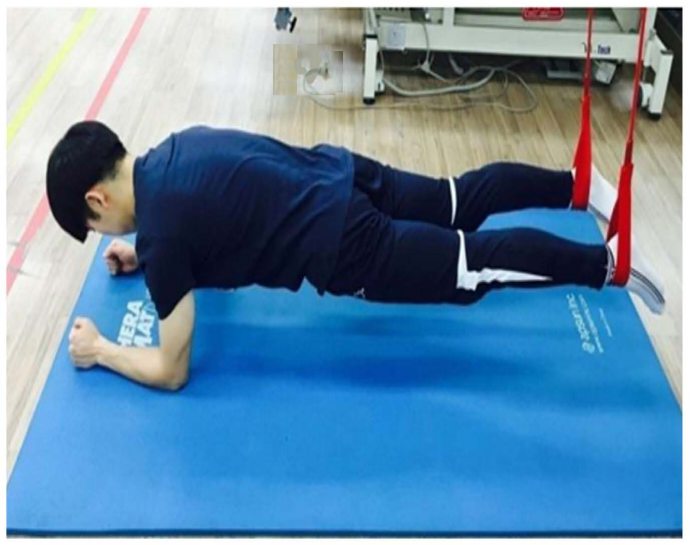

(c)

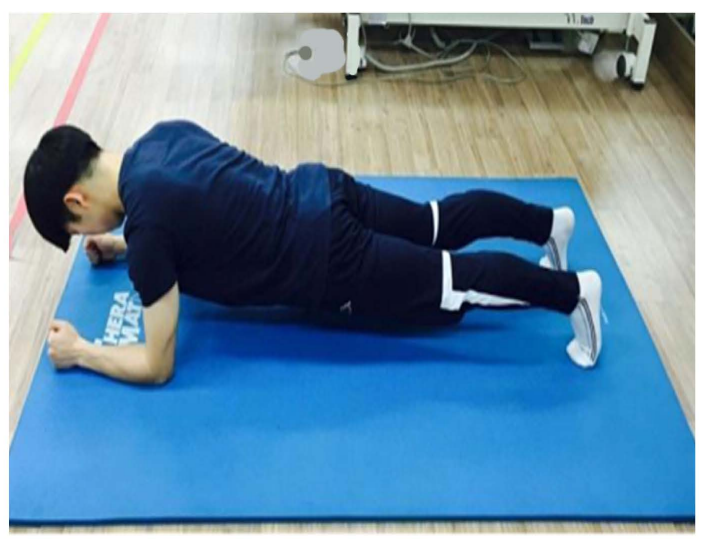

(b)

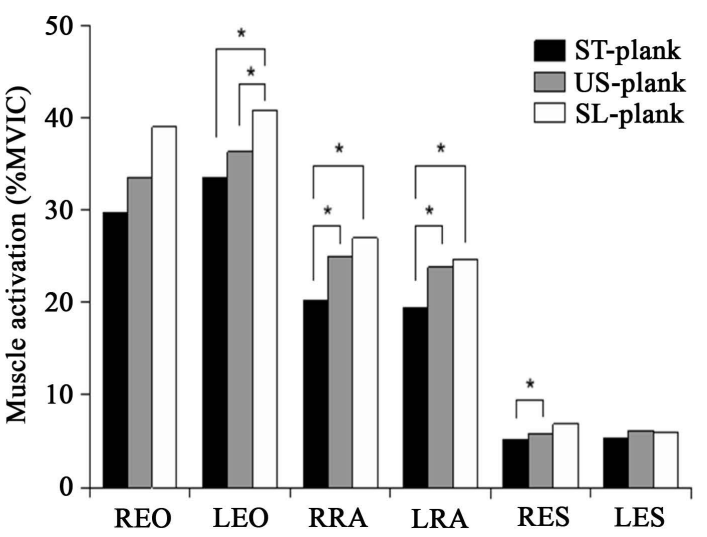

(d)

Figure 6. Comparison of the muscle activities in terms of maximum voluntary isometric contraction (MVIC) of the plank exercise (b) on stable ground (ST), (a) unstable ground (US), and sling suspension device (SL) (c) over REO, LEO, RRA, LRA, RES, and LES muscles. Note: the mark $\left(^{*}\right)$ shows the \% MVIC is $\left.\mathrm{P}<0.05\right)$. Adapted with permission from [60], Copyright (c) 2012 Korean Academy of Physical Therapy Rehabilitation Science.

Grindstaff and coworker compared the activation of transversus abdominis (TrA) in individuals with LBP in sling-based bridging exercise on stable and unstable surface. The results implied that although both ways improved the TrA activation during SET, the unstable surface led to higher activation [62].

Based on these conclusions, beneficent pattern of movements can be achieved by focusing on the weak muscles requiring more training [23]. Moreover, recently Wagner and coworkers measured the TrA thickness by utilizing a non-invasive ultrasound during resting and sling exercise. They found that sling training significantly increased the TrA thickness which reflected an improvement in its function [63].

The muscle training process by SET is including open- and closed kinetic-chain exercises. In particular, the distal parts are not fixed and weight load are absent in the open-chain (OKCE) and vice-versa in the closed kinetic-chain (CKCE) [64]. Thus performance of both training in the SET led to co-activation of agonists, synergists, and antagonists muscles resulting in ultimate improvement from the training [65]. For example, the current exercise program for the athletes involves combination of OKCEs and CKCEs to improve their performance and enhance their body strength (e.g. core-, upper- and lower) along with reduction in the injuries rate [66].

Specifically, in the CKCEs, the lever arm and its related torque can be easily controlled upon adjusting the length of the used ropes and/or moving the sling suspension point vertically over the patient body. This is more easy, efficient, and productive than the traditional CKCEs [67]. That intriguingly drives the muscle strengthen with minimum pain for upper and lower limbs regardless of the instability of the joints. Notably, CKCEs is more favored and commonly used in the SET compared with the OCKEs owing to presence of heavy tension on the dynamic stability of the joints along with simultaneous muscles exercises. 


\subsection{Pain Relief and Muscles Relaxation}

The pain relief is one of the most important factors in the rehabilitation process. It is noteworthy that based on the gate control theory, using vibration with the SET is playing an important role in the pain relief (Figure 7) [68]. In particular, vibration stimulation decreases the pain by its simultaneous interference with the pain signals to the brain. This is achieved by activation of the larger diameter $A \beta$ nerve fibers via non-noxious (e.g. Vibration) stimuli which subsequently drives closing a neural "gate" to nociceptive signals upon stimulation the mechanoreceptors, including but not limited the Pacinian corpuscles, primary endings of the muscle spindle, and Meissner's corpuscles in the skin, subcutaneous tissues, and bone. This is subsequently led to decrease the pain [69]. In addition, SET is used successfully for treatment of pregnant women with a pelvic girdle pain, whiplashassociated disorders (WAD), and neck pain in post-traumatic stress disorder patients [70]. Interestingly these cases can be barely cured with the traditional approaches. Figure 8 depicts the screening effect of McKenzie and SET on pain relief during treatment of LBP. Specifically, the results demonstrated that, SET has a prominent effect in decreasing pain relative to the common McKenzie method. Moreover, SET is more facile and flexible rehabilitation approach compared with the McKenzie.

Intriguingly, Zhu and coworkers found that, SET is superior to the thermo-magnetic therapy with /without drug therapy in pain relief [71]. In addition to improvement muscles functions, SET can also be valid for long and short-term use to reduce pain as studied over various medical trials [71].

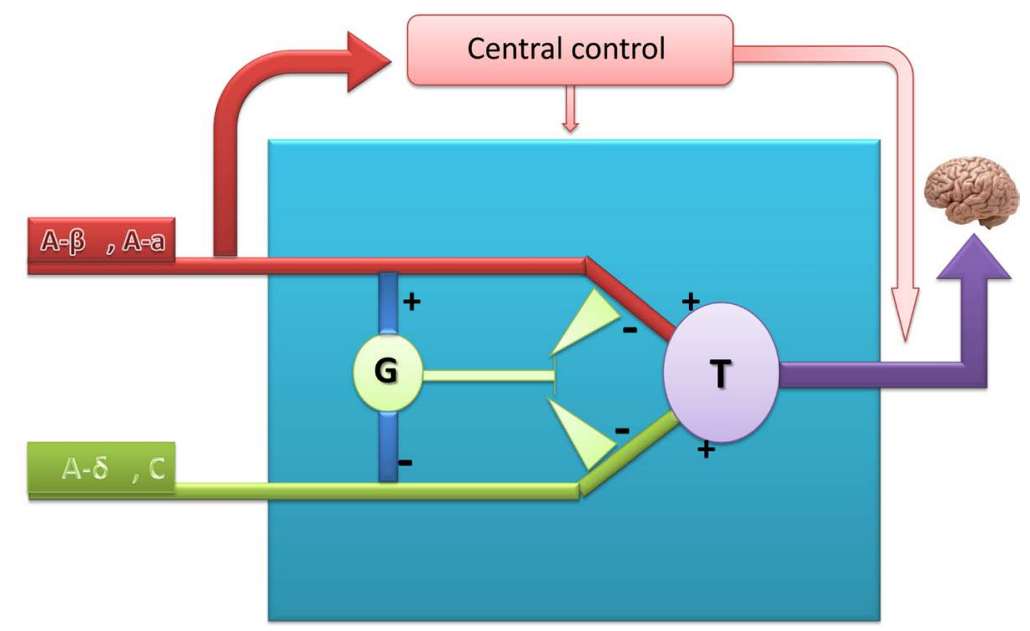

(a)

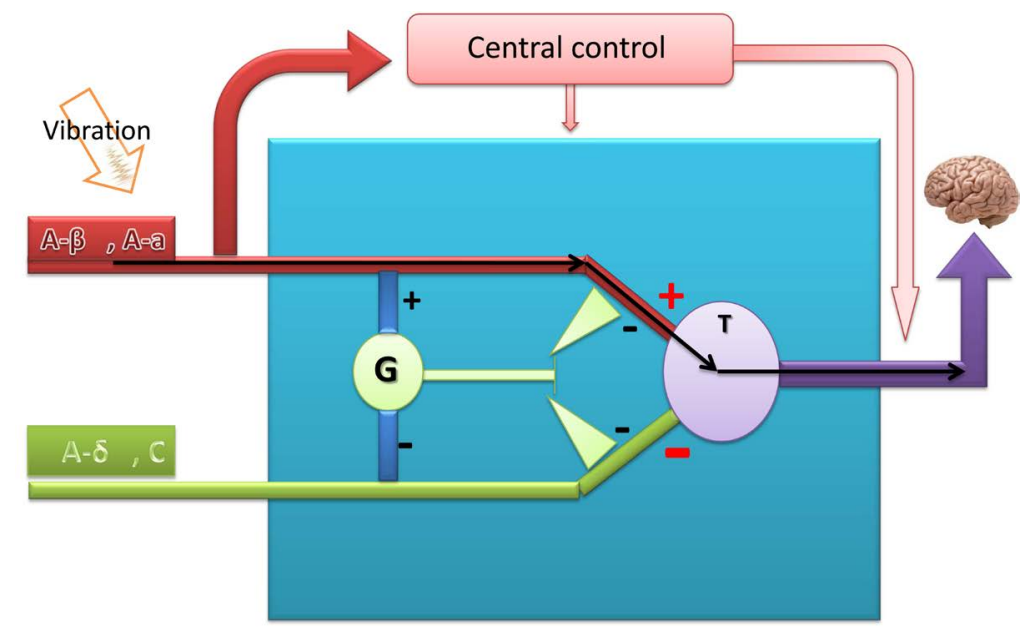

(b)

Figure 7. Scheme represents the gate control theory for decreasing pain during muscle activity under vibration. 


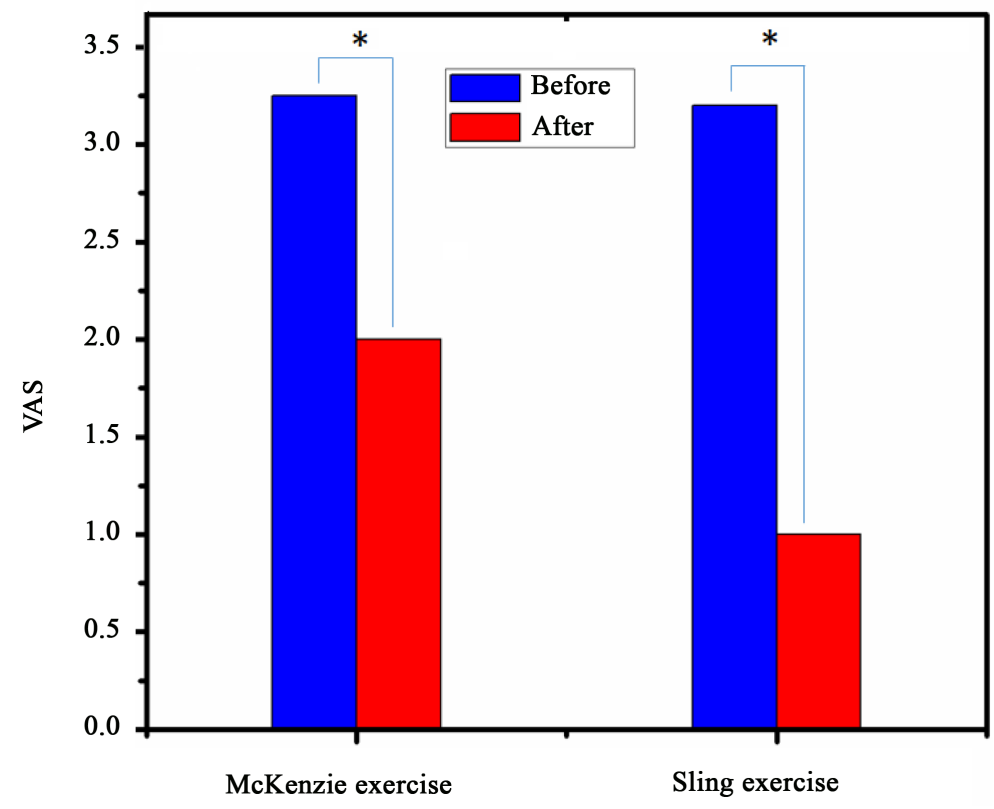

Figure 8. Changes of pain before and after sling and McKenzie exercise. The comparison of the results before and after training was analysed statistically by using the t-test methods with setting the analytical significance level to 0.05 . Note: the sign $(*)$ indicates the $\mathrm{P}=0.246$. This image was drawn based on the data from [8].

It is noteworthy that, the deficiency in the sensorimotor and/or stabilizing is a deceive reason behind increasing pain during rehabilitation process. The SET is well known for its high activity for the painless restoration for the body balance and stability. Recently, Oh and coworkers reported that, the Neurac intervention have a substantial effect onto decreasing pain along with improvement the function of shoulder relative to traditional intervention [9], Interestingly, using six weeks of sling exercises led to decreasing the pain intensity and improved the disability level of LBP [53].

On the other hand, muscles spasm is one of the most pivotal parameter that hinders and slows down the rehabilitation process especially among old and athletics. SET have a significant effect onto enhancement muscle relaxation for enabling rehabilitation. This is achieved by hanging a part of the body to get the required position for relaxation, enabling smooth movements for the patient limbs. These enhance relaxation, prevent contraction, and increase blood flow in the suspended muscles. That is an important step for successful and comfortable rehabilitation process [23].

\subsection{Range of Motion Restoration}

The protracted ailments such as fractious and sport injuries restrict motion of the infected joints and muscles. This can be treated with a wide range of physiotherapy interventions including but not limited mechanical shock waves, electro-stimulation, and heat modalities along with particular exercises. SET is able to effectively facilitate various training procedures required for range motion restoration (ROM) with less pain. For example, Gravity-eliminated (GE) entails moving the affected joints and muscles passively allowing their gradual stretching to increase ROM. Chang and coworkers, systematically compared between the effect of SET and McKenzie exercise on the patients with chronic neck pain. Intriguingly, they found that the ROM by SET is significantly superior to McKenzie especially in flexion, extension, and right/left lateral flexion (Table 3) [8]. Similarly, the lumbar stabilization exercise using the Neurac sling improved the functional performance of CLBP [4].

Furthermore, the SET has a substantial effect in improving the ROM for patients with total knee replacement relative to traditional interventions Particularly, the SET exhibits approximately 1.7, 1.6, and, 1.1-folds enhancement in quadriceps, hamstring, and flexion respectively compared with traditional exercise (Table 4) [18]. Recently, Oh and coworkers reported that, the Neurac intervention enhanced the ROM of Shoulder significantly in the patient with an acute-phase subacromial impingement syndrome [9]. 
Table 3. Comparison of the ROM between sling and McKenzie groups.This drawing is based on the data reported in [8].

\begin{tabular}{|c|c|c|c|c|c|}
\hline Neck motion & & Sling exercise group & McKenzie exercise group & $t$ & $\boldsymbol{P}$ \\
\hline & Before & $6.70(2.96)$ & $6.43(3.47)$ & & \\
\hline \multirow[t]{3}{*}{ Flexion } & After & $7.80(2.30)$ & $8.25(2.80)$ & 0.033 & 0.974 \\
\hline & Before-after & $1.10(2.27)$ & $1.81(2.40)$ & & \\
\hline & Before & $7.20(3.57)$ & $7.00(4.50)$ & & \\
\hline \multirow[t]{3}{*}{ Extension } & After & $8.15(1.63)$ & $8.06(2.80)$ & 0.924 & 0.369 \\
\hline & Before-after & $0.95(2.27)$ & $1.06(3.56)$ & & \\
\hline & Before & $6.70(2.91)$ & $7.25(5.26)$ & & \\
\hline \multirow[t]{3}{*}{ Right lateral flexion } & After & $8.10(1.63)$ & $8.56(3.04)$ & 1.981 & 0.072 \\
\hline & Before-after & $1.40(1.89)$ & $1.31(3.69)$ & & \\
\hline & Before & $6.35(2.04)$ & $6.44(3.57)$ & & \\
\hline \multirow[t]{2}{*}{ Left lateral flexion } & After & $8.00(2.31)$ & $8.44(2.00)$ & 0.126 & 0.902 \\
\hline & Before-after & $1.65(1.58)$ & $2.00(2.30)$ & & \\
\hline
\end{tabular}

Table 4. Comparison of pre/post tests for sling exercises and traditional interventions, this drawing is based on the data reported in [18].

\begin{tabular}{|c|c|c|c|c|c|}
\hline Category & Group & Period & $\mathbf{M} \pm \mathbf{S D}$ & $t$ & $\boldsymbol{P}$ \\
\hline \multirow{2}{*}{ Flexion } & SEG & $\begin{array}{l}\text { Pre } \\
\text { Post }\end{array}$ & $\begin{array}{c}68.75 \pm 12.64 \\
110.42 \pm 11.77\end{array}$ & 13.72 & 0.000 \\
\hline & CG & $\begin{array}{l}\text { Pre } \\
\text { Post }\end{array}$ & $\begin{array}{c}70.83 \pm 8.75 \\
99.33 \pm 13.20\end{array}$ & 7.19 & 0.000 \\
\hline \multirow{2}{*}{ Extension } & SEG & $\begin{array}{l}\text { Pre } \\
\text { Post }\end{array}$ & $\begin{array}{l}-7.00 \pm 4.90 \\
-3.25 \pm 2.42\end{array}$ & 2.96 & 0.130 \\
\hline & CG & $\begin{array}{l}\text { Pre } \\
\text { Post }\end{array}$ & $\begin{array}{l}-9.00 \pm 5.74 \\
-5.08 \pm 4.08\end{array}$ & 3.33 & 0.000 \\
\hline
\end{tabular}

SEG: Sling Exercise Group, CG: Control Group.

\subsection{Stabilizing System Training}

The joints stability is considered one of the most vital factors required for preventing joint injuries and improve their function. This can be achieved via stability exercises through SET ascribed to its ability to reduce the pain and the load on the joints in parallel with contracting their surrounding muscles [72]. In this context, various studies reported the significant effect of SET on the trunk stabilization. For instance, the weakness of the global and/or local muscles is one of the main reasons behind LBP (Figure 9). This problem can be resolved by the SET exercises due to its effect in activating and improving trunk muscles function [11] [13] [53].

Furthermore, SET showed a significant effect in enhancing the stability of torso in osteoporosis patients with chronic back pain relative to traditional rehabilitation route. Interestingly, $Y u$ and coworkers investigated the effect of bridge exercise with sling (BSE), ball (BBE), and normal bridging (NBE) on activation of the trunk muscles (global mobilizer and local stabilizer) of patient with LBP [73] (Figure 10). The results clearly revealed that, the activity of trunk muscles by BSE is superior to both BBE and NBE respectively in supination and pronation positions (Figure 11 and Figure 12), This is due to the great effect of unstable surfaces enhance muscles activity by SET compared with stable surfaces [74]. Hwangbo and coworkers systematically investigated the effect of trunk stabilization exercise by using SET and mat exercise (MEG) on the patients with hemiplegia [11]. 


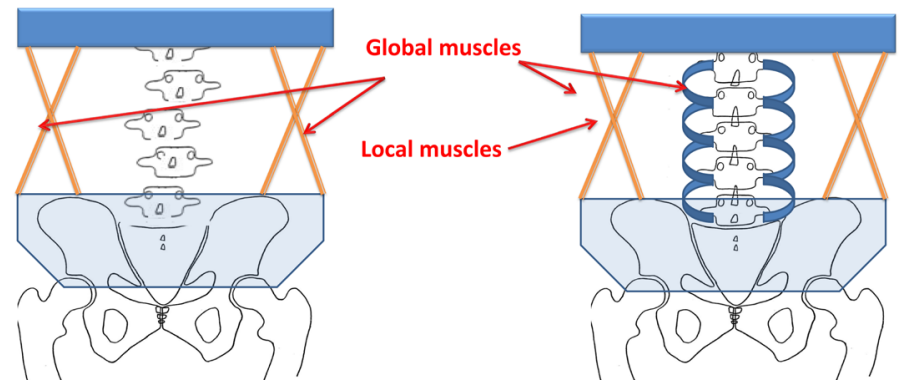

Figure 9. Schematic draw illustrates the relationship between global and local muscles along with stabilization.

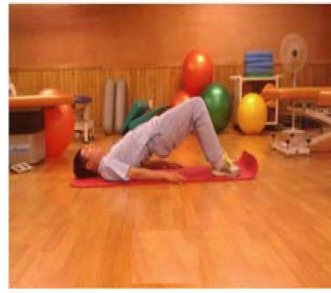

(a)

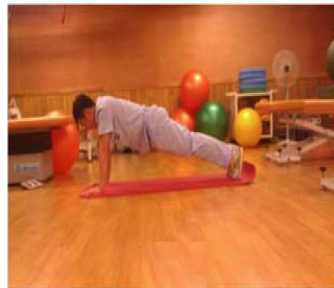

(d)

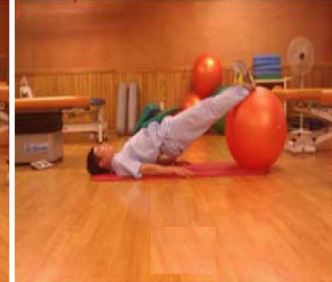

(b)

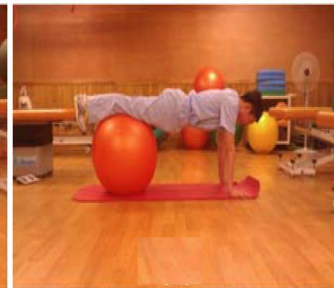

(e)

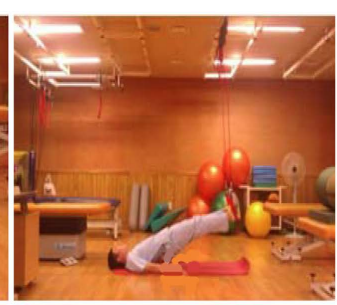

(c)

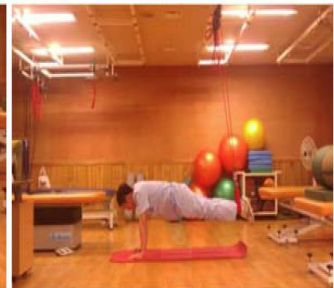

(f)

Figure 10. Comparison of the bridging exercises with (a) normal; (b) ball and (c) sling suspension in supine. Bridge exercise with (d) normal; (e) ball exercise, and (f) sling suspension in prone. Adapted with permission from [73], Copyright (c) 2012 by the Society of Physical Therapy Science.
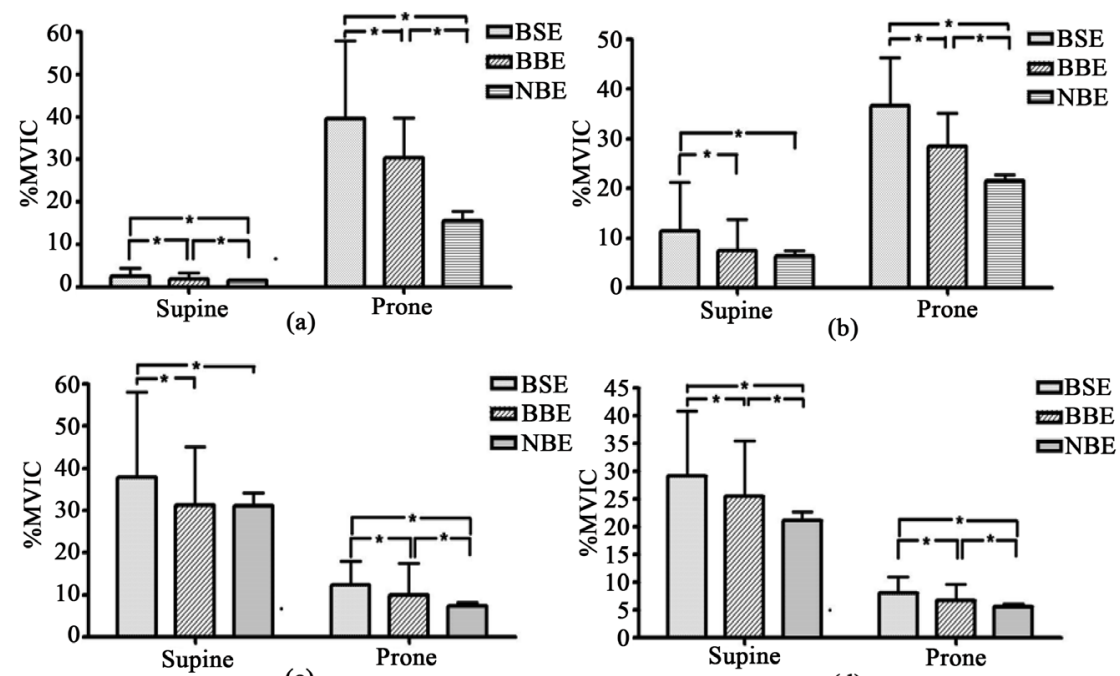

(c)

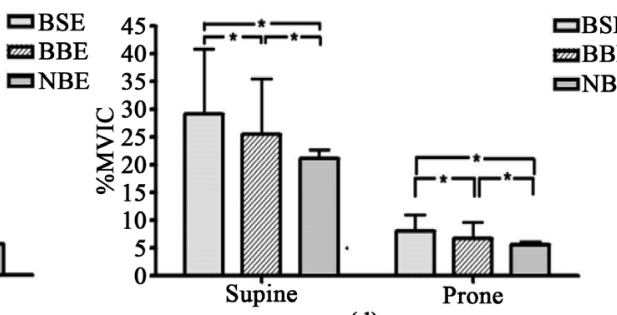

(d)

Figure 11. The MVIC during BSE, BBE, and NBE on (a) internal oblique muscle; (b) rectus abdominis muscle, (c) multifidus muscle, and (d) erector spinae muscle. Adapted with permission from [71], Copyright (C) 2012 by the Society of Physical Therapy Science. 


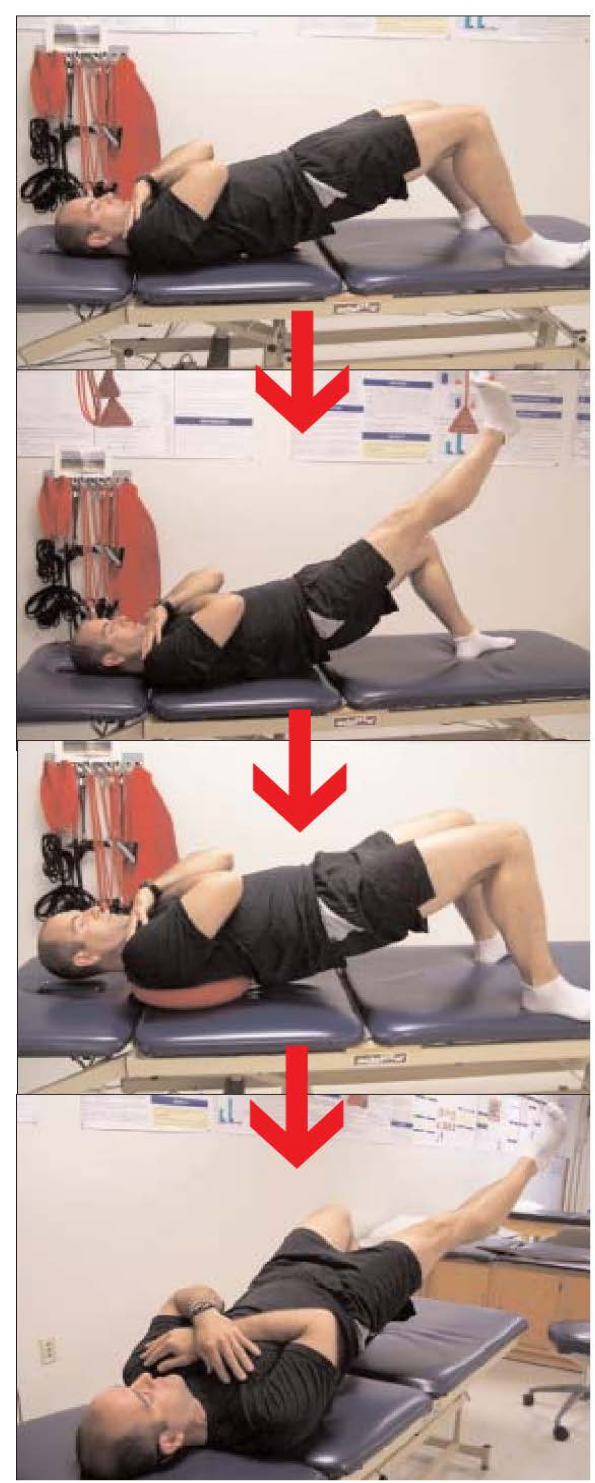

(a)

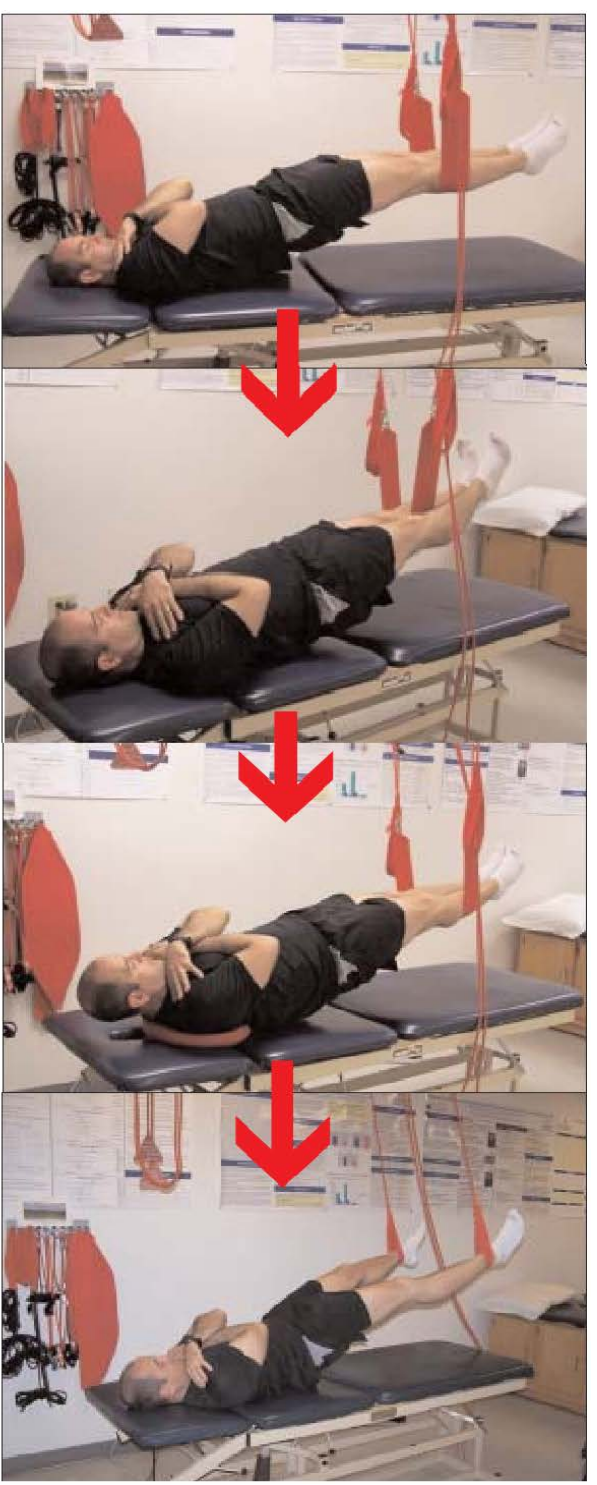

(b)

Figure 12. Photo images represent the traditional bridge exercise and sling bridge exercise. (a) Traditional bridge exercise; (b) Sling-bridge exercise.

Specifically, SET depicted a considerable improvement on adjustment of trunk muscles facilitating both balance and gait. Recently the same group compared the effect of bridge exercise with a sling and vibration (BESV) and without vibration (BES) on lumbar stabilization. The overall comparisons were conducted on an unstable base of support. They found that, BESV activated both internal obliques (IO) and external obliques (EO) muscles significantly relative to BES [12].

On the other hand various reports concluded the significant effect of stability exercises by SET to improve the athletics performance as well as avoiding and/or decreasing their injures. For example, Seiler and coworkers found that, SET exercise with unstable base augmented the torso stabilization considerably. That subsequently led to further increment in the balance and throwing velocity of the players [51]. This is because of the unique effect of SET in enhancing neuromuscular control along with joint stabilization.

\section{Future Prospective of SET}

Although the great advances in using SET in various therapeutic and diagnostic applications, there are various 
limitations are currently existed and need to be solved in the near future. This is including absence of systematic research information about using SET along with other therapeutic modalities such as electrotherapy. Also, scaling up the SET for training the weak muscles including the second level of muscle strength $(<2 / 5)$. Eventually the research articles about using SET for rehabilitation of the athletics in addition to and improvement their performance should be highlighted enough.

\section{Conclusion}

In summary, this review summarizes the SET with its correlated factors, conditions, and applications. The using of SET in balance/sensorimotor training, muscle training, pain relief/muscles relaxation, range of motion restoration, and stabilizing exercises is also discussed in detail. In addition, SET may be utilized in clinical diagnosis of various musculoskeletal disorders. The whole review is endorsed and supported with myriad immaculate examples as well as emphasis over most recent advancements in SET. We hope this article be the first guideway of SET for the rehabilitation centers as well as researchers in this area.

\section{References}

[1] Praveen Kumar, P.R. and Venkata, P. (2005) Fundamental of Physiotherapy. Jaypee Brothers Medical Publishers, New Delhi. http://eprints.uwe.ac.uk/1003

[2] Elvestad, P., Ingersoll, C.D., Katch, V.L., Katch, F.I., Weltman, A. and Redcord, A. (2008) The Effects of a Worksite Neuromuscular Activation Program on Sick Leave: A Pilot Study. Medicine and Science in Sports and Exercise, 40, S434-S435. http://dx.doi.org/10.1249/01.mss.0000322849.44057.21

[3] Kim, M.-K., Jung, J.-M., Chang, J.-S. and Lee, S.-K. (2012) Radiographic Imaging Analysis after Sling Exercises for Hemiplegic Shoulder Subluxation. Journal of Physical Therapy Science, 24, 1099-1101. http://dx.doi.org/10.1589/jpts.24.1099

[4] Kim, J.H., Kim, Y.E., Bae, S.H. and Kim, K.Y. (2013) The Effect of the Neurac Sling Exercise on Postural Balance Adjustment and Muscular Response Patterns in Chronic Low Back Pain Patients. Journal of Physical Therapy Science, 25, 1015-1019. http://dx.doi.org/10.1589/jpts.25.1015

[5] Yi, S.-J. and Kim, J.-S. (2015) The Effects of Respiratory Muscle Strengthening Exercise Using a Sling on the Amount of Respiration. Journal of Physical Therapy Science, 27, 2121. http://dx.doi.org/10.1589/jpts.27.2121

[6] Lee, J.-H. and Kim, S.-Y. (2014) Comparative Effectiveness of Schroth Therapeutic Exercise versus Sling Therapeutic Exercise in Flexibility, Balance, Spine Angle and Chest Expansion in Patient with Scoliosis. Journal of the Korean Society of Physical Medicine, 9, 11-23. http://dx.doi.org/10.13066/kspm.2014.9.1.11

[7] Yun, S., Kim, Y.L. and Lee, S.M. (2015) The Effect of Neurac Training in Patients with Chronic Neck Pain. Journal of Physical Therapy Science, 27, 1303. http://dx.doi.org/10.1589/jpts.27.1303

[8] Seo, S.-C., Choi, J.-Y., Joo, M.-Y., Kim, J.-H. and Chang, S.-K. (2012) Effects of Sling Exercise and McKenzie Exercise Program on Neck Disability, Pain, Muscle Strength and Range of Motion in Chronic Neck Pain. Physical Therapy Rehabilitation Science, 1, 40-48.

[9] Kim, S.-Y., Kang, M.-H., Lee, D.-K. and Oh, J.-S. (2015) Effects of the Neurac® Technique in Patients with Acute-Phase Subacromial Impingement Syndrome. Journal of Physical Therapy Science, 27, 1407. http://dx.doi.org/10.1589/jpts.27.1407

[10] Chang, W.-D., Huang, W.-S., Lee, C.-L., Lin, H.-Y. and Lai, P.-T. (2014) Effects of Open and Closed Kinetic Chains of Sling Exercise Therapy on the Muscle Activity of the Vastus Medialis Oblique and Vastus Lateralis. Journal of Physical Therapy Science, 26, 1363-1366. http://dx.doi.org/10.1589/jpts.26.1363

[11] Park, J.H. and Hwangbo, G. (2014) The Effect of Trunk Stabilization Exercises Using a Sling on the Balance of Patients with Hemiplegia. Journal of Physical Therapy Science, 26, 219-221. http://dx.doi.org/10.1589/jpts.26.219

[12] Park, J., Lee, S. and Hwangbo, G. (2015) The Effects of a Bridge Exercise with Vibration Training and an Unstable Base of Support on Lumbar Stabilization. Journal of Physical Therapy Science, 27, 63. http://dx.doi.org/10.1589/jpts.27.63

[13] Lee, J.S. and Lee, H.G. (2014) Effects of Sling Exercise Therapy on Trunk Muscle Activation and Balance in Chronic Hemiplegic Patients. Journal of Physical Therapy Science, 26, 655. http://dx.doi.org/10.1589/jpts.26.655

[14] Lee, J.-S., Yang, S.-H., Koog, Y.-H., Jun, H.-J., Kim, S.-H. and Kim, K.-J. (2014) Effectiveness of Sling Exercise for Chronic Low Back Pain: A Systematic Review. Journal of Physical Therapy Science, 26, 1301-1306. http://dx.doi.org/10.1589/jpts.26.1301

[15] Schmoll, S., Hahn, D. and Schwirtz, A. (2008) Die Behandlung von chronischem LWS-Schmerz mithilfe des SET- 
Konzeptes (Sling-Exercise-Therapy). Bewegungstherapie und Gesundheitssport, 24, 52-59. http://dx.doi.org/10.1055/s-2008-1004726

[16] Yun, K., Lee, S. and Park, J. (2015) Effects of Closed Chain Exercises for the Lumbar Region Performed with Local Vibration Applied to an Unstable Support Surface on the Thickness and Length of the Transverse Abdominis. Journal of Physical Therapy Science, 27, 101-103. http://dx.doi.org/10.1589/jpts.27.101

[17] Jeong, S.Y., Chung, S.H. and Shim, J.H. (2014) Comparison of Upper Trapezius, Anterior Deltoid, and Serratus Anterior Muscle Activity during Push-Up plus Exercise on Slings and a Stable Surface. Journal of Physical Therapy Science, 26, 937-939. http://dx.doi.org/10.1589/jpts.26.937

[18] Bae, C.-H., Jung, Y.-W., Lee, D.-W. and Cho, S.-H. (2014) The Effect of Sling Exercise on Muscular Strength and Range of Motion in Female Patients who Received Total Knee Replacement. Journal of the Korea Academia-Industrial Cooperation Society, 15, 4395-4403. http://dx.doi.org/10.5762/kais.2014.15.7.4395

[19] Maeo, S., Chou, T., Yamamoto, M. and Kanehisa, H. (2014) Muscular Activities during Sling- and Ground-Based Push-Up Exercise. BMC Research Notes, 7, 192. http://dx.doi.org/10.1186/1756-0500-7-192

[20] Eom, M.Y., Chung, S.H. and Ko, T.S. (2013) Effects of Bridging Exercise on Different Support Surfaces on the Transverse Abdominis. Journal of Physical Therapy Science, 25, 1343-1346. http://dx.doi.org/10.1589/jpts.25.1343

[21] De Mey, K., Danneels, L., Cagnie, B., Borms, D., T’Jonck, Z., Van Damme, E. and Cools, A.M. (2014) Shoulder Muscle Activation Levels during Four Closed Kinetic Chain Exercises with and without Redcord Slings. The Journal of Strength \& Conditioning Research, 28, 1626-1635. http://dx.doi.org/10.1519/JSC.0000000000000292

[22] Guthrie, R.J., Grindstaff, T.L., Croy, T., Ingersoll, C.D. and Saliba, S.A. (2012) The Effect of Traditional Bridging or Suspension-Exercise Bridging on Lateral Abdominal Thickness in Individuals with Low Back Pain. Journal of Sport Rehabilitation, 21, 151-160. http://www.ncbi.nlm.nih.gov/pubmed/22100462

[23] Kirkesola, G. (2000) Sling Exercise Therapy (S-E-T)—A Concept for Active Treatment and Training for Ailments in the Musculoskeletal Apparatus. Fysioterapeuten, No. 12, 9-16.

[24] Liu, H., Yao, K., Zhang, J., Li, L., Wu, T., Brox, J.I. and He, C. (2013) Sling Exercise Therapy for Chronic Low-Back Pain. Cochrane Database of Systematic Reviews, No. 9, Article No. CD010689. http://dx.doi.org/10.1002/14651858.cd010689

[25] Precautions, A.-R. (1935) Poliomyelitis and Cerebro-Spinal Fever in Germany. BMJ, 2, 311.

[26] McArdle, W.D., Katch, F.I. and Katch, V.L. (2010) Exercise Physiology: Nutrition, Energy, and Human Performance. Lippincott Williams \& Wilkins, Philadelphia.

[27] Brox, J.I., Staff, P.H., Ljunggren, A.E. and Brevik, J.I. (1993) Arthroscopic Surgery Compared with Supervised Exercises in Patients with Rotator Cuff Disease (Stage II Impingement Syndrome). BMJ, 307, 899-903. http://dx.doi.org/10.1136/bmj.307.6909.899

[28] Brox, J.I., Gjengedal, E., Uppheim, G., Bøhmer, A.S., Brevik, J.I., Ljunggren, A.E. and Staff, P.H. (1999) Arthroscopic Surgery versus Supervised Exercises in Patients with Rotator Cuff Disease (Stage II Impingement Syndrome). Journal of Shoulder and Elbow Surgery, 8, 102-111. http://dx.doi.org/10.1016/S1058-2746(99)90001-0

[29] Gao, B., Rong, X., Liang, D. and Li, L. (2008) The Effect of Sling Exercise Therapy on Low Back Pain Caused by Exercises Training. Chinese Journal of Rehabilitation Medicine, 23, 1095-1097.

[30] Li, L. and Feng, Z.-Y. (2015) Clinical Observation of Treating Chronic Nonspecific Low Back Pain with Baduanjin Combining Sling Exercise Therapy. Rheumatism and Arthritis, 4, 16-19.

[31] Kisner, C. and Colby, L.A. (2012) Therapeutic Exercise: Foundations and Techniques. F.A. Davis Company, Philadelphia.

[32] Choi, Y. and Kang, H. (2013) The Effects of Sling Exercise Using Vibration on Trunk Muscle Activities of Healthy Adults. Journal of Physical Therapy Science, 25, 1291-1294. http://dx.doi.org/10.1589/jpts.25.1291

[33] Lee, S.-K. (2013) The Effects of Vibration Stimuli Applied to the Shoulder Joint on the Activity of the Muscles around the Shoulder Joint. Journal of Physical Therapy Science, 25, 1407-1409. http://dx.doi.org/10.1589/jpts.25.1407

[34] Kim, E.-R., Oh, J.-S. and Yoo, W.-G. (2014) Effect of Vibration Frequency on Serratus Anterior Muscle Activity during Performance of the Push-Up plus with a Redcord Sling. Journal of Physical Therapy Science, 26, 1275-1276. http://dx.doi.org/10.1589/jpts.26.1275

[35] Muceli, S., Farina, D., Kirkesola, G., Katch, F. and Falla, D. (2011) Reduced Force Steadiness in Women with Neck Pain and the Effect of Short Term Vibration. Journal of Electromyography and Kinesiology, 21, 283-290. http://dx.doi.org/10.1016/j.jelekin.2010.11.011

[36] De Oliveira, C.B., de Medeiros, Í.R.T., Frota, N.A.F., Greters, M.E. and Conforto, A.B. (2008) Balance Control in Hemiparetic Stroke Patients: Main Tools for Evaluation. Journal of Rehabilitation Research and Development, 45, 1215-1226. http://dx.doi.org/10.1682/JRRD.2007.09.0150 
[37] Karatas, M., Çetin, N., Bayramoglu, M. and Dilek, A. (2004) Trunk Muscle Strength in Relation to Balance and Functional Disability in Unihemispheric Stroke Patients. American Journal of Physical Medicine \& Rehabilitation, 83, 8187. http://dx.doi.org/10.1097/01.PHM.0000107486.99756.C7

[38] Lin, D., Nussbaum, M.A., Seol, H., Singh, N.B., Madigan, M.L. and Wojcik, L.A. (2009) Acute Effects of Localized Muscle Fatigue on Postural Control and Patterns of Recovery during Upright Stance: Influence of Fatigue Location and Age. European Journal of Applied Physiology, 106, 425-434. http://dx.doi.org/10.1007/s00421-009-1026-5

[39] Cetin, N., Bayramoglu, M., Aytar, A., Surenkok, O. and Yemisci, O.U. (2008) Effects of Lower-Extremity and Trunk Muscle Fatigue on Balance. The Open Sports Medicine Journal, 2, 16-22. http://dx.doi.org/10.2174/1874387000802010016

[40] Paillard, T. (2012) Effects of General and Local Fatigue on Postural Control: A Review. Neuroscience \& Biobehavioral Reviews, 36, 162-176. http://dx.doi.org/10.1016/j.neubiorev.2011.05.009

[41] Voight, M. and Cook, G. (2010) Clinical Application of Closed Kinetic Chain Exercise. Journal of Sport Rehabilitation, 5, 25-44.

[42] O’Sullivan, P., Dankaerts, W., Burnett, A., Straker, L., Bargon, G., Moloney, N., Perry, M. and Tsang, S. (2006) Lumbopelvic Kinematics and Trunk Muscle Activity during Sitting on Stable and Unstable Surfaces. Journal of Orthopaedic \& Sports Physical Therapy, 36, 19-25. http://dx.doi.org/10.2519/jospt.2006.36.1.19

[43] Lehman, G.J., MacMillan, B., MacIntyre, I., Chivers, M. and Fluter, M. (2006) Shoulder Muscle EMG Activity during Push up Variations on and off a Swiss Ball. Dynamic Medicine, 5, 7. http://dx.doi.org/10.1186/1476-5918-5-7

[44] McGill, S.M. and Karpowicz, A. (2009) Exercises for Spine Stabilization: Motion/Motor Patterns, Stability Progressions, and Clinical Technique. Archives of Physical Medicine and Rehabilitation, 90, 118-126. http://dx.doi.org/10.1016/j.apmr.2008.06.026

[45] Jung, K.-S., Cho, H.-Y. and In, T.-S. (2016) Trunk Exercises Performed on an Unstable Surface Improve Trunk Muscle Activation, Postural Control, and Gait Speed in Patients with Stroke. Journal of Physical Therapy Science, 28, 940 944. http://dx.doi.org/10.1589/jpts.28.940

[46] Marshall, P. and Murphy, B. (2006) Changes in Muscle Activity and Perceived Exertion during Exercises Performed on a Swiss Ball. Applied Physiology, Nutrition, and Metabolism, 31, 376-383. http://dx.doi.org/10.1139/h06-006

[47] McGuine, T.A. and Keene, J.S. (2006) The Effect of a Balance Training Program on the Risk of Ankle Sprains in High School Athletes. The American Journal of Sports Medicine, 34, 1103-1111. http://dx.doi.org/10.1177/0363546505284191

[48] Schiftan, G.S., Ross, L.A. and Hahne, A.J. (2015) The Effectiveness of Proprioceptive Training in Preventing Ankle Sprains in Sporting Populations: A Systematic Review and Meta-Analysis. Journal of Science and Medicine in Sport, 18, 238-244. http://dx.doi.org/10.1016/j.jsams.2014.04.005

[49] Zech, A., Hübscher, M., Vogt, L., Banzer, W., Hänsel, F. and Pfeifer, K. (2010) Balance Training for Neuromuscular Control and Performance Enhancement: A Systematic Review. Journal of Athletic Training, 45, 392-403.

[50] Yoon, S.-D., Sung, D.-H. and Park, G.D. (2015) The Effect of Active Core Exercise on Fitness and Foot Pressure in Taekwondo Club Students. Journal of Physical Therapy Science, 27, 509-511. http://dx.doi.org/10.1589/jpts.27.509

[51] Saeterbakken, A.H., Van den Tillaar, R. and Seiler, S. (2011) Effect of Core Stability Training on Throwing Velocity in Female Handball Players. The Journal of Strength \& Conditioning Research, 25, 712-718. http://dx.doi.org/10.1519/JSC.0b013e3181cc227e

[52] Prokopy, M.P., Ingersoll, C.D., Nordenschild, E., Katch, F.I., Gaesser, G.A. and Weltman, A. (2008) Closed-Kinetic Chain Upper-Body Training Improves Throwing Performance of NCAA Division I Softball Players. The Journal of Strength \& Conditioning Research, 22, 1790-1798. http://dx.doi.org/10.1519/JSC.0b013e318185f637

[53] You, Y.-L., Su, T.-K., Liaw, L.-J., Wu, W.-L., Chu, I.-H. and Guo, L.-Y. (2015) The Effect of Six Weeks of Sling Exercise Training on Trunk Muscular Strength and Endurance for Clients with Low Back Pain. Journal of Physical Therapy Science, 27, 2591-2596. http://dx.doi.org/10.1589/jpts.27.2591

[54] Tsauo, J.-Y., Cheng, P.-F. and Yang, R.-S. (2008) The Effects of Sensorimotor Training on Knee Proprioception and Function for Patients with Knee Osteoarthritis: A Preliminary Report. Clinical Rehabilitation, 22, 448-457. http://dx.doi.org/10.1177/0269215507084597

[55] Behm, D.G. Leonard, A.M, Young, W.B., Bonsey, W.A.C. and MacKinnon, S.N. (2005) Trunk Muscle Electromyographic Activity with Unstable and Unilateral Exercises. The Journal of Strength \& Conditioning Research, 19, 193-201. http://dx.doi.org/10.1519/00124278-200502000-00033

[56] Yun, K.H. and Kim, K. (2013) Effect of Craniocervical Flexion Exercise Using Sling on Thickness of Sternocleidomastoid Muscle and Deep Cervical Flexor Muscle. Journal of the Korean Society of Physical Medicine, 8, $253-261$. http://dx.doi.org/10.13066/kspm.2013.8.2.253 
[57] Marshall, P.W. and Murphy, B.A. (2005) Core Stability Exercises on and off a Swiss Ball. Archives of Physical Medicine and Rehabilitation, 86, 242-249. http://dx.doi.org/10.1016/j.apmr.2004.05.004

[58] Imai, A., Kaneoka, K., Okubo, Y., Shiina, I., Tatsumura, M., Izumi, S. and Shiraki, H. (2010) Trunk Muscle Activity during Lumbar Stabilization Exercises on Both a Stable and Unstable Surface. Journal of Orthopaedic \& Sports Physical Therapy, 40, 369-375. http://dx.doi.org/10.2519/jospt.2010.3211

[59] Petrofsky, J.S., Batt, J., Davis, N., Lohman, E., Laymon, M., De Leon, G.E., Roark, H., Tran, T.M., Ayson, E.G. and Vigeland, K.M. (2007) Core Muscle Activity during Exercise on a Mini Stability Ball Compared with Abdominal Crunches on the Floor and on a Swiss Ball. Journal of Applied Research in Clinical and Experimental Therapeutics, 7, 255.

[60] Lee, J., Jeong, K., Lee, H., Shin, J., Choi, J., Kang, S. and Lee, B.-H. (2016) Comparison of Three Different Surface Plank Exercises on Core Muscle Activity. Physical Therapy Rehabilitation Science, 5, 29-33. http://dx.doi.org/10.14474/ptrs.2016.5.1.29

[61] Lee, D., Park, J. and Lee, S. (2015) Effects of Bridge Exercise on Trunk Core Muscle Activity with Respect to Sling Height and Hip Joint Abduction and Adduction. Journal of Physical Therapy Science, 27, 1997-1999. http://dx.doi.org/10.1589/jpts.27.1997

[62] Saliba, S.A., Croy, T., Guthrie, R., Grooms, D., Weltman, A. and Grindstaff, T.L. (2010) Differences in Transverse Abdominis Activation with Stable and Unstable Bridging Exercises in Individuals with Low Back Pain. North American Journal of Sports Physical Therapy: NAJSPT, 5, 63-73.

[63] Lükens, J., Boström, K.J., Puta, C., Schulte, T.L. and Wagner, H. (2015) Using Ultrasound to Assess the Thickness of the Transversus Abdominis in a Sling Exercise. BMC Musculoskeletal Disorders, 16, 203. http://dx.doi.org/10.1186/s12891-015-0674-3

[64] Lephart, S.M. and Henry, T.J. (1996) The Physiological Basis for Open and Closed Kinetic Chain Rehabilitation for the Upper Extremity. Journal of Sport Rehabilitation, 5, 71-87.

[65] Harter, R.A. (1996) Clinical Rationale for Closed Kinetic Chain Activities in Functional Testing and Rehabilitation of Ankle Pathologies. Journal of Sport Rehabilitation, 5, 13-24.

[66] Uçar, M., Koca, I., Eroglu, M., Eroglu, S., Sarp, U., Arik, H.O. and Yetisgin, A. (2014) Evaluation of Open and Closed Kinetic Chain Exercises in Rehabilitation Following Anterior Cruciate Ligament Reconstruction. Journal of Physical Therapy Science, 26, 1875-1878. http://dx.doi.org/10.1589/jpts.26.1875

[67] Dannelly, B., Otey, S., Croy, T., Harrison, B., Rynders, C., Hertel, J. and Weltman, A. (2011) Effectiveness of Traditional and Sling Exercise Strength Training in Novice Women. The Journal of Strength \& Conditioning Research, 25, S81-S82. http://dx.doi.org/10.1519/JSC.0b013e318202e473

[68] Melzack, R. and Wall, P.D. (1965) Pain Mechanisms: A New Theory. Science, 150, 971-979. http://dx.doi.org/10.1126/science.150.3699.971

[69] Shimada, Y., Davis, R., Matsunaga, T., Misawa, A., Aizawa, T., Itoi, E., Zilberman, Y., Cosendai, G. and Ripley, A.M. (2006) Electrical Stimulation Using Implantable Radiofrequency Microstimulators to Relieve Pain Associated with Shoulder Subluxation in Chronic Hemiplegic Stroke. Neuromodulation: Technology at the Neural Interface, 9, 234238. http://dx.doi.org/10.1111/j.1525-1403.2006.00065.x

[70] Yu, S.H. and Park, S.D. (2015) The Effects of a Neck Musculoskeletal Intervention on Neck Pain Levels and Depression in Post-Traumatic Stress Disorder Patients. Journal of Physical Therapy Science, 27, 1975-1978. http://dx.doi.org/10.1589/jpts.27.1975

[71] Yue, Y.-S., Wang, X.-D., Xie, B., Li, Z.-H., Chen, B.-L., Wang, X.-Q. and Zhu, Y. (2014) Sling Exercise for Chronic Low Back Pain: A Systematic Review and Meta-Analysis. PLoS ONE, 9, e99307. http://dx.doi.org/10.1371/journal.pone.0099307

[72] Kline, J.B., Krauss, J.R., Maher, S.F. and Qu, X. (2013) Core Strength Training Using a Combination of Home Exercises and a Dynamic Sling System for the Management of Low Back Pain in Pre-Professional Ballet Dancers: A Case Series. Journal of Dance Medicine \& Science, 17, 24-33. http://dx.doi.org/10.12678/1089-313X.17.1.24

[73] Kang, H.K., Jung, J.H. and Yu, J.H. (2012) Comparison of Trunk Muscle Activity during Bridging Exercises Using a Sling in Patients with Low Back Pain. Journal of Sports Science and Medicine, 11, 510-515.

[74] Stokes, I.A., Gardner-Morse, M.G. and Henry, S.M. (2011) Abdominal Muscle Activation Increases Lumbar Spinal Stability: Analysis of Contributions of Different Muscle Groups. Clinical Biomechanics, 26, 797-803. http://dx.doi.org/10.1016/j.clinbiomech.2011.04.006 


\section{Abbreviations and Acronyms}

SET: Sling Exercise Therapy

ROM: Range of Motion

LBP: Low Back Pain

CLBP: Chronic Low Back Pain

EMG: Electromyography

REO: Right External Oblique Muscle

LEO: Left External Oblique Muscle

LRA: Left Rectus Abdominal Muscle

RES: Right Erector Spinal Muscle

LES: Left Erector Spinal Muscle

RRA: Right Erector Spinal Muscle

TrA: Transversus Abdominis Muscle

OKCE: Open Kinetic Chain Exercises

CKCE: Closed Kinetic Chain Exercises

WAD: Whiplash-Associated Disorders

GE: Gravity-Eliminated

BSE: Bridge Exercise with Sling

BBE: Bridge Exercise with Ball

NBE: Normal Bridging Exercise

MEG: Mat Exercise Group

BESV: Bridge Exercise with a Sling and Vibration

Vas: Visual Analog Scale

BES: Bridge Exercise without Vibration

IO: Internal Obliques Muscle

EO: External Obliques Muscle

\section{Submit or recommend next manuscript to SCIRP and we will provide best service for you:}

Accepting pre-submission inquiries through Email, Facebook, LinkedIn, Twitter, etc.

A wide selection of journals (inclusive of 9 subjects, more than 200 journals)

Providing 24-hour high-quality service

User-friendly online submission system

Fair and swift peer-review system

Efficient typesetting and proofreading procedure

Display of the result of downloads and visits, as well as the number of cited articles

Maximum dissemination of your research work

Submit your manuscript at: http://papersubmission.scirp.org/ 